\title{
Moral Competence and Perceived Moral Distress among Health Care Professionals in an Urban Health Care Setting; Facility Based Study
}

\author{
Varalakshmi Manchana \\ Assistant Professor, School of Medical Sciences, University of Hyderabad, India
}

\begin{abstract}
Background: Caring for patients and their families in their vulnerable moments is a great challenge to health care providers. Moral distress occurs when health care professionals cannot carry out what they believe to be ethically appropriate for patient care. Imbalance between authority and responsibility, frustrating patterns in health care team and inability to make ethical decision making for patient care are more commonly associated ethical dimensions for practice resulting to moral distress. Unresolved ethical problems have been linked to increased experience of moral distress and reduced job satisfaction. Aim: The present study aimed to identify the perceptions of moral distress and associated levels of job satisfaction among Registered Nurses $(R N)$ and physicians in an urban area hospital. Methods: Registered Nurses $(n=65)$ and physicians $(n=25)$ between the age group of 22-58 years, with minimum of two years of work experience, working in the government urban area hospital, who were willing to participate were included in the study. After securing informed consent, data was collected on demographic information and on moral distress and job satisfaction. Structured Questionnaire was used to collect data on; Demographic information, moral distress and Job satisfaction. Four Point Lickert scale was used to measure the frequency and intensity of morally distressing situations, which was scored between 0-4 (never to always). The intensity was measured from 0-4 (no effect to great extent in disturbance). Results: The mean scores were found to be 90.86 in Nurses and it was 60.85 in Physicians. 68\% of the Nurses and $52 \%$ of the Physicians were not satisfied with the quality of patient care provided. Among them $69 \%$ of RN expressed powerlessness in decision making, while $8 \%$ of the physicians agreed for the powerlessness experience in patient care decision making. $58 \%$ of the nurses were dissatisfied with the type of decision-making in patient care; where as $58 \%$ of the Physicians were fully satisfied with patient care decisions implemented. Conclusion: Moral distress was found to be experienced by both nurses and physicians. But physicians show comparatively lower levels of moral distress to nurses in the same units and setting. The study provides evidence that the job satisfaction and moral distress are negatively associated and the perceptions of quality of health care rendered and there is dire need to adopt resilient measures in health care settings.
\end{abstract}

Keywords: Moral distress, Job satisfaction; Resilience, Quality Health care, Health care Professionals

\section{Introduction}

Moral distress is a wide spread problem among health care providers. Moral distress occurs when: You know the ethically appropriate action to take, but you are unable to act upon it. You act in a manner contrary to your personal and professional values, which undermines your integrity and authenticity (Jamelton, 1984) ${ }^{1}$. It is the most frequently experienced barrier among health care providers, yet it is usually a neglected area for the concern and action. Unresolved moral distress, regardless of reasons is shown to have negative consequences influencing individual physical, psycho-social health, performance, job morale and ultimately patient care. Caring for patients and their families in their vulnerable moments is a great challenge for health care providers. Moral distress results when health care professionals cannot carry out what they believe to be ethically appropriate for patient care. Nurses are frequently perceived "to follow orders", which senses lack of control over the decisions affecting patient care. Widening mismatch between authority and responsibility and have no control over patient care decision making may gives rise to job dissatisfaction, emotional anguish and moral distress. The ethical distress if unresolved, results to poor commitment towards the job responsibilities, increased absenteeism and frequent turnover. The distress aggravates when they had to make difficult choices between following rules or following conscience, where the healthcare providers feels inability to preserve all interests and values at stake. Resolution of moral distress is a possible means strengthening ethical practice in healthcare. Jameton (1984) ${ }^{1}$ first coined the term moral distress to capture the inability of nurses to act on what they believe is the right thing to do because of internal and/or institutional constraints.

\section{Literature Review / Background}

Regardless of varying perceptions about moral distress, it always carry negative consequences, contributing to emotional distress such as frustration, anguish, irritability, intolerance etc. This in turn may result to withdrawal of self from team work, patient care, negative attitude formation towards the institutional policy, poor quality in patient care, decreasing job satisfaction and even attrition in nursing. Hamric and colleagues suggested that (Epstein EG, Hamric ab,2009) $)^{2}$, when nurses experience moral distress they may respond in at least one of three ways; they may withdraw from ethically challenging situations, change positions and / or continue to raise objections and voice concerns about situations. Moral distress is associated with job dissatisfaction, turnover, mental anguish and decreased job morale. However little research 


\section{International Journal of Science and Research (IJSR) \\ ISSN (Online): 2319-7064}

Index Copernicus Value (2015): 78.96 | Impact Factor (2015): 6.391

is done on what contribute to moral distress and measures for resolution. Lack of conceptual activity has hampered action on it. Individuals may experience initial and reactive moral distress (Corley, M. C.2002, 2005) ${ }^{3.4}$. Reactive moral distress is a response to not acting on initial frustration experienced either encountering institutional obstacles or value conflicts. Unresolved moral distress, regardless of reasons has been shown to have negative consequences contributing to emotional distress, poor morale, withdrawal, absenteeism, inadequate performance and decreased job satisfaction resulting to poor commitment to quality patient care.

\section{Aim:}

The study aims to examine the perceptions of moral distress and its association with Job satisfaction among Registered nurses \& Physicians in the government area hospital.

\section{Objectives:}

1. Assess the perceived moral distress among the registered nurses and physicians working in the urban based government area hospital

2. Assess the perceived job satisfaction in the registered nurses and physicians working in the urban based government area hospital

3. Associate the moral distress with job satisfaction and quality patient care.

Research Questions addressed;

- What kinds of situations are likely to trigger Moral distress?

- Is the intensity of Moral distress related to Job satisfaction?

- Which internal and external factors are associated with Moral distress?

- Does the Perceived Moral distress vary between Nurses and Doctors in the similar health setting?

- Does the frequency and intensity of Moral distress influence Quality patient care?

\section{Materials \& Methods}

Research Design: Cross sectional correlation study.

Sampling: 65 nursing staff and 25 physicians working in the Government urban area hospital, between the age group of 22-58 years, with minimum of two years of work experience, willing to participate were included in the study. The data collection was undertaken between November 2013 to January 2014.

Tools: Structured Questionnaire was used to collect data on;

1. Demographic information

2. Frequency \& Intensity of moral distress and factors associated

3. Level of Job satisfaction

Study was initiated after securing ethical and institutional permissions and informed consent from the study participants. Data collection was done after ascertaining the reliability $(\mathrm{r}=.89)$ and validity of the tool by the subject experts from Nursing, Psychology and statistics.

The study examines the perceived moral distress among Nurses and Doctors in a selected health care setting and its association with Job satisfaction and quality patient care.

The 5 Point Lickert scale was used to measure the frequency and intensity of Moral distress;

The tool was prepared based on Corley's Moral distress scale.

Scores were distributed as: Frequency ranges from 0 (never) to 4(always);

Intensity ranges from 0 (none) to 4 (great extent);

\section{Major Findings of the Study}

Moral Distress was assessed on four areas;

1. Patient care decision making capacity

2. Fair distribution of work load and working hours

3. Working environment

4. Professional development \& Opportunities.

Job Satisfaction was assessed on 10 selected components;

Moral distress was found to be experienced by both nurses and physicians. But its frequency \& intensity, its perceived impact differed between Nurses and Doctors working in the similar units.

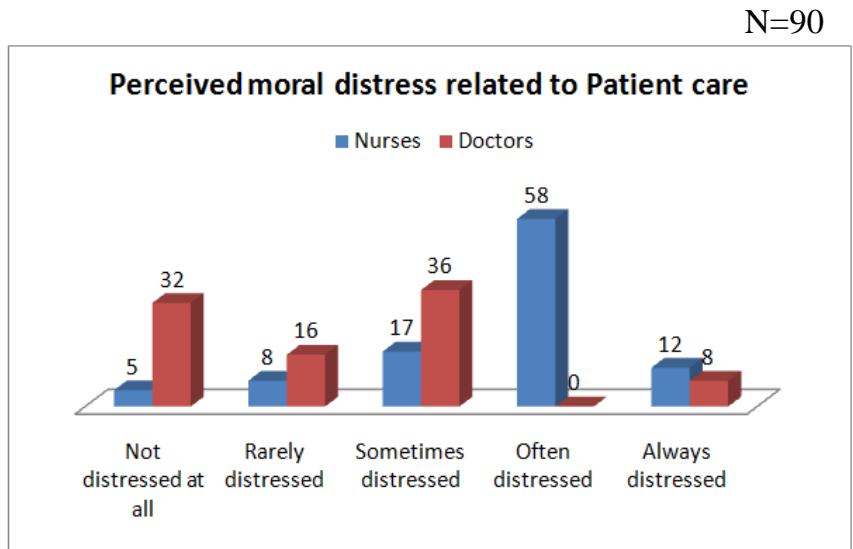

Figure 1: Percentage distribution of the perceived Moral distress related to Patient care among Health care Professionals

The study indicates $58 \%$ of the RN (Figure 1) were often distressed and $36 \%$ of the Dr agree upon sometimes feeling distressed in relate to patient care. $32 \%$ of the doctors and $5 \%$ of the nurses agreed that there is no situation of feeling un-distressed. 
International Journal of Science and Research (IJSR)

ISSN (Online): 2319-7064

Index Copernicus Value (2015): 78.96 | Impact Factor (2015): 6.391

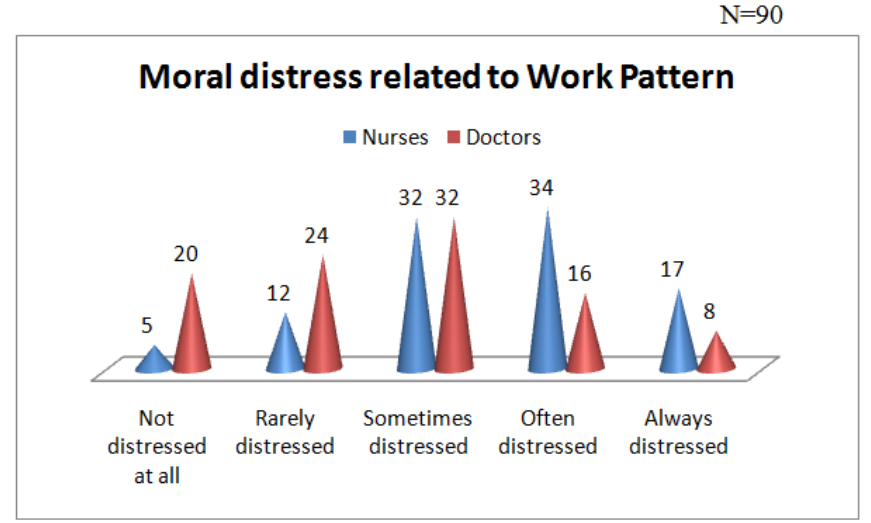

Figure 2: Percentage distribution of the Moral distress related to work pattern in Health care Professionals The study shows $32 \%$ of each RN (Figure 2) \& Dr agreed upon feeling distressed sometimes. $17 \%$ of the nurses and $8 \%$ of the doctors reported of always feeling distressed in regard to the work pattern.

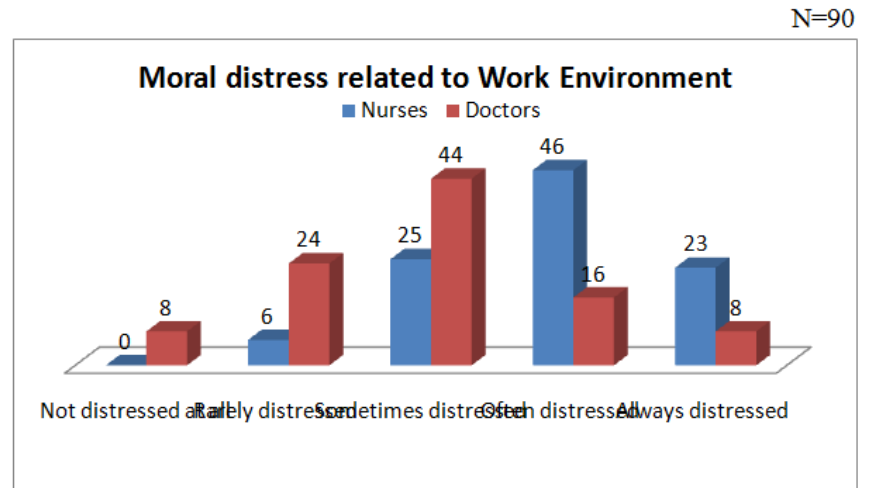

Figure 3: Percentage distribution of the Moral distress related to work environment in Health care Professionals The study shows $44 \%$ of the doctors sometimes distressed and RN (Figure 3) \& $46 \%$ of the RN often feel distressed and none of them agreed for not having un-distressed situation at work. About $8 \%$ of the doctors reported of not feeling distressed at all.

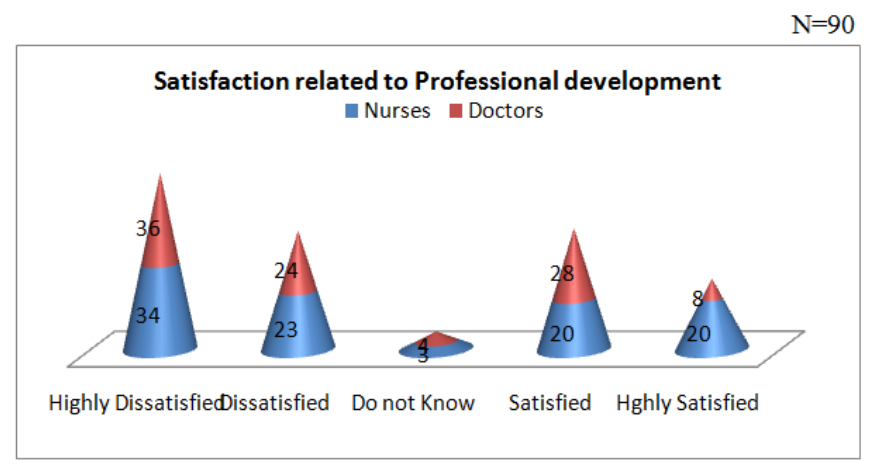

Figure 4: Percentage distribution of the Satisfaction levels related to Professional development

The study shows $36 \%$ of the doctors and $34 \%$ of the RN (Figure 4) were highly dissatisfied. Only $4 \%$ and $3 \%$ of Doctors/Nurses respectively said they were not sure. About $8 \%$ of the doctors and $20 \%$ of the nurses were highly satisfied with the professional development opportunities available.

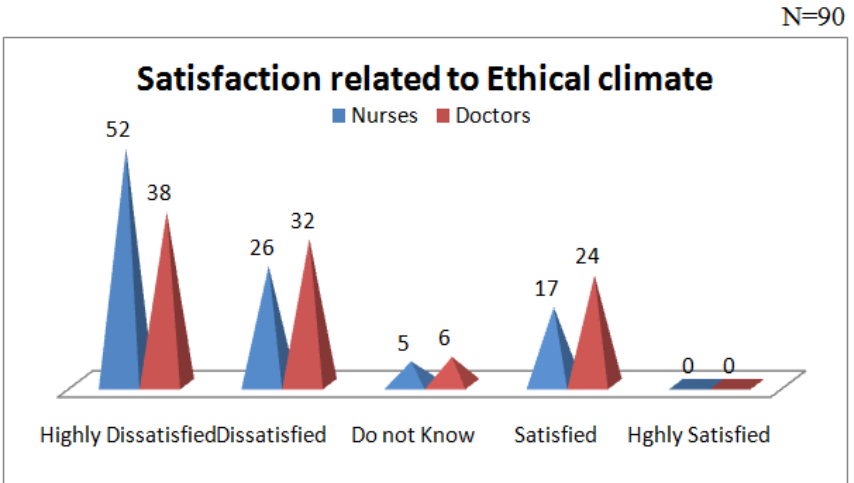

Figure 5: Percentage distribution of the Satisfaction levels related to Ethical Climate of the working Institution

The study shows $52 \%$ of the RN (Figure 5) \& $38 \%$ of the Dr agree upon high level of dissatisfaction related to the ethical environment in the institution. None of the nurses $\&$ doctors was highly satisfied with the working ethical environment.

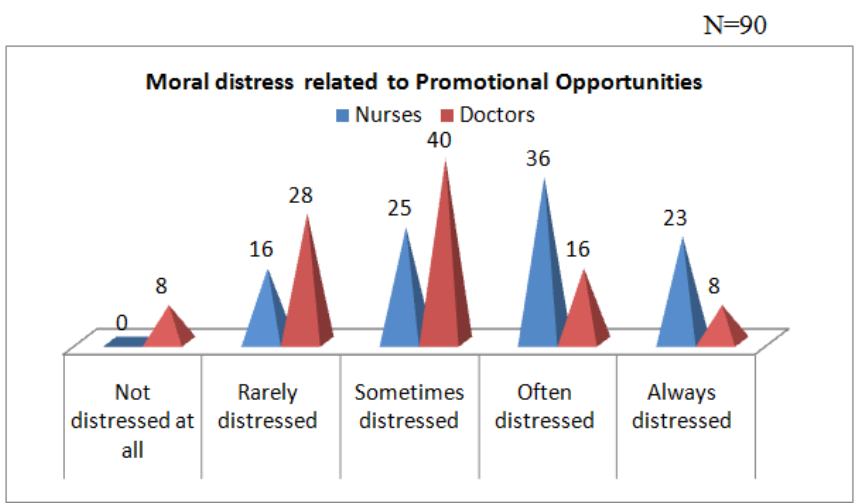

Figure 6: Percentage distribution of the perceived Moral distress related to Promotional Opportunities

The study indicates that majority of $40 \%$ of RN (Figure 6) and $25 \%$ of the doctors agreed that they were sometimes distressed. None of the RN and $8 \%$ of the Dr agreed they have never felt un distressed. $23 \%$ of RN \& $8 \%$ of Drs said they almost always feel morally distressed in regard to their promotional opportunities. 
Table 1: Perceived Job Satisfaction was measured in Ten (10) areas as follows

\begin{tabular}{|c|c|c|c|c|c|c|c|c|c|c|c|}
\hline \multirow{2}{*}{$\begin{array}{l}\mathbf{S} . \\
\mathbf{N}\end{array}$} & \multirow{2}{*}{$\begin{array}{l}\text { Measured Item for Job } \\
\text { satisfaction }\end{array}$} & \multicolumn{2}{|c|}{1} & \multicolumn{2}{|c|}{2} & \multicolumn{2}{|c|}{3} & \multicolumn{2}{|c|}{4} & \multicolumn{2}{|c|}{5} \\
\hline & & $\mathbf{R N}$ & DR & RN & DR & $\mathbf{R N}$ & DR & RN & DR & RN & DR \\
\hline 1 & Working conditions & 11 & 2 & 22 & 4 & 21 & 8 & 8 & 5 & 3 & 6 \\
\hline 2 & Pay scale & 4 & 2 & 6 & 4 & 2 & 8 & 30 & 2 & 23 & 9 \\
\hline 3 & $\begin{array}{l}\text { Professional } \\
\text { advancement }\end{array}$ & $\mathbf{0}$ & $\mathbf{0}$ & 13 & 2 & 22 & 9 & 15 & 6 & 15 & 8 \\
\hline 4 & $\begin{array}{l}\text { Interpersonal relations } \\
\text { and team support }\end{array}$ & 18 & 2 & 24 & 3 & 16 & 3 & 5 & 12 & 2 & 5 \\
\hline 5 & Work load & 10 & 2 & 24 & 4 & 20 & 8 & 8 & 5 & 3 & 6 \\
\hline 6 & Professional support & 15 & 9 & 22 & 8 & 12 & 3 & 11 & 4 & 5 & 1 \\
\hline 7 & $\begin{array}{l}\text { Opportunities for } \\
\text { continuing education and } \\
\text { training }\end{array}$ & 0 & 0 & 13 & 2 & 22 & 9 & 15 & 6 & 15 & 8 \\
\hline 8 & $\begin{array}{l}\text { Novelty \& Opportunities } \\
\text { to update clinical skills }\end{array}$ & 10 & 2 & 24 & 4 & 20 & 8 & 8 & 5 & 3 & 6 \\
\hline 9 & $\begin{array}{l}\text { Participation in decision } \\
\text { making }\end{array}$ & 15 & 9 & 22 & 8 & 12 & 3 & 11 & 4 & 5 & 1 \\
\hline 10 & Job security & 0 & $\mathbf{0}$ & 13 & 2 & 22 & 9 & 15 & 6 & 15 & 8 \\
\hline
\end{tabular}

5 = Highly Satisfied; 4 = Very much Satisfied; 3 = Satisfied: 2 = Somewhat Satisfied; 1 = Not at all Satisfied

Study shows (Table.1), 32 of the nurses and 19 of the doctors were satisfied with the working conditions. None of them expressed satisfaction with job security though it is government based organization due to the changing social trends. Majority of $(n=42)$ of the nurses and only 5 doctors expressed dissatisfaction related to the interpersonal relationships. $\mathrm{N}=90$

Table 2: Perceived impact of Ethical distress on Quality care:

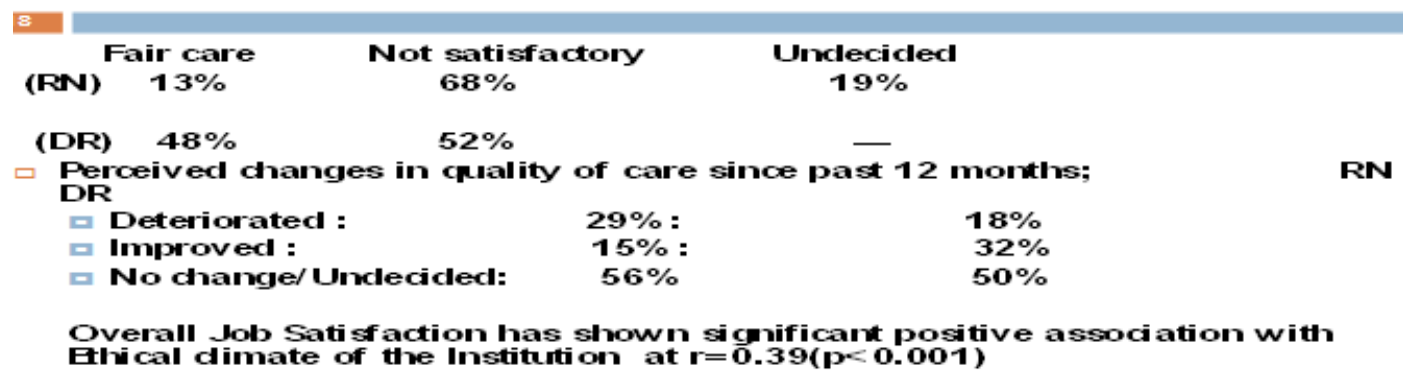

The study indicates that majority of $52 \%$ of Dr (Table.2) and $68 \%$ of RN were not satisfied with the Quality Patient care. Half of the Dr \& RN agreed that they are not sure of any change happened in quality patient care since last one year.

Table 3: Mean Moral Distress among Health Professionals

\begin{tabular}{|c|c|}
\hline Discipline & Mean \pm SD \\
\hline Registered Nurses & $61.6 \pm 33$ \\
\hline Doctors & $61.6 \pm 33$ \\
\hline
\end{tabular}

The mean scores among nurses are more compared to mean moral distress in doctors (Table.3) 


\section{International Journal of Science and Research (IJSR) \\ ISSN (Online): 2319-7064}

Index Copernicus Value (2015): 78.96 | Impact Factor (2015): 6.391

\section{$\mathrm{N}=90$}

Table 4: Perceived barriers to Quality Patient care

$\begin{array}{lcc} & \text { Nurses } & \text { Physicians } \\ \text { Limited staff : } & \mathbf{6 7} \% & \mathbf{2 5} \% \\ \text { Increased work burden: } & \mathbf{4 5} \% & \mathbf{3 2} \% \\ \text { Too many Patients : } & \mathbf{5 6} \% & \mathbf{5 0} \% \\ \text { Inadequate resources } & 37 \% & \mathbf{2 9} \% \\ \text { Unfair work distribution: } & \mathbf{3 6} \% & \mathbf{1 2} \% \\ \text { Work Stress } & \mathbf{3 4} \% & \mathbf{1 4} \% \\ \begin{array}{l}\text { Powerlessness } \\ \text { in decision making: }\end{array} & \mathbf{6 9} \% & \mathbf{8} \% \\ \begin{array}{l}\text { Inadequate support system } \\ \text { in crisis: }\end{array} & \mathbf{5 4} \% & \mathbf{6} \%\end{array}$

The study shows that majority of $67 \%$ of RN (Table.4) and $25 \%$ of Dr agreed of having limited staff as a barrier to quality patient care. More than half of the (RN: $56 \%$, Dr:50\%) opined of having too many patients as a barrier to patient care. $69 \%$ of the RN said they feel powerless in decision making, whereas only $8 \%$ of the doctors agreed for powerlessness.

\section{Discussion}

The study found that the more favorable the moral autonomy, the higher the level of job satisfaction reported by the nurses. Considering the relationship between the moral distress at work and job attrition, it is found a significant relationship between higher the moral distress and poor job satisfaction. A study by (Zuzelo, P. R. $(2007)^{7}$ discusses about the strategies for resolving moral distress, which in turn leads to a lower employee turnover, greater organizational commitment, and better job performance. Olson ${ }^{4}$ considers the ethical climate an organizational variable which can be managed and modified in order to improve the work environment. The ethical climate provides a basis for ethical decision making in organizations. When healthcare organizations enable their employees to talk to others about difficult issues, such as those faced by nurses in the care of patients, and allow them to feel that they can consult their colleagues, managers or clinicians, they create conditions which promote ethical thinking, ethical dialogue, hope and problem-solving (C. E. Fletcher,2001, Rushton, C. H. $2006)^{8,9}$. Working environment facilitating moral resilient measures favors in promoting job satisfaction and enhancing the health care efficiency rendered by the nurses and doctors for quality patient care.

\section{Conclusion}

The study demonstrated that the health professionals frequently encounter moral distress in various clinical settings. Actual moral distress was significantly higher in nurses comparative to doctors. Was found to be experienced by both nurses and physicians. But physicians show lower levels of moral distress compared to Registered nurses in the same units and setting. The study provides evidence that the job satisfaction is negatively associated with moral distress, where as it showed positive association with ethical climate. Moral distress is associated with burnout and intention to leave a position. By understanding its root causes, interventions can be tailored to minimize moral distress with the ultimate goal of enhancing patient care, staff satisfaction, and retention.

\section{Limitations}

The study was limited to one single health setting and the sample size between nurses and doctors couldn't be same due to the unwillingness of the equal number from the doctors. The study did not assess personal \& professional impact and also the impact of acute care and general settings.

\section{Recommendations}

With the ultimate goal of safe and quality patient care, it is the need of the hour for the refinement of measures to address the moral distress and to empower health care professionals with remedies to rise above Moral distress;

\section{Acknowledgements}

The author wish to acknowledge the permission accorded by the Superintendent and the support extended by the R.M.O of the Hospital for conducting the study and the junior faculty Ms. Gayathri, who assisted in data collection and would extend special appreciation to all the Nurses and Doctors for their willingness and cooperation for participating in the study.

\section{References}

[1] Jameton, A. Nursing practice: The Ethical issues. Englewood Cliffs, NJ: Prentice Hall;1984

[2] Epstein EG, Hamric, AB. Moral Distress, Moral Residue and the Crescendo Effect. J Clin Ethics.2009;20(4):330-334

[3] Corley, M. C. Nurse Moral Distress: A Proposed Theory and research agenda. Nursing Ethics.2002; 9(6): 636-650

[4] Corley, M. C., Minick, P., Elswick, R. K., \& Jacobs, M. Nurse moral distress and ethical work environment. Nursing Ethics.2005; 12(4), 381-390.

[5] Olson, L. L. Hospital nurses' perceptions of the ethical climate of their work setting. Image: Journal of Nursing Scholarship.2005; 30(4), 345-349.

[6] Storch, J. L., Rodney, P., Pauly, R., Brown, H., \& Starzomski, R. Listening to nurses' moral voices: Building a quality health care environment. Canadian Journal of Nursing Leadership.2002; 15(4), 7-16.

[7] Zuzelo, P.R. Exploring the moral distress of registered nurses. Nursing Ethics.2007; 14(3), 344-359.

[8] C. E. Fletcher, "Hospital RNs' job satisfactions and dissatisfactions, "Journal of Nursing Administration.2001; (31)6:324-331,

[9] Rushton, C. H. Defining and addressing moral distress. AACN Advanced Critical Care.2006; 17(2), 161-168 